\title{
Erratum to: A comparative study of DA-9601 and misoprostol for prevention of NSAID-associated gastroduodenal injury in patients undergoing chronic NSAID treatment
}

\author{
Oh Young Lee • Dae-Hwan Kang • Dong Ho Lee • Il-Kwun Chung • \\ Jae Young Jang · Jin-Il Kim • Jin-Woong Cho · Jong-Sun Rew $\cdot$ Kang-Moon Lee • \\ Kyoung Oh Kim • Myung-Gyu Choi $\cdot$ Sang-Woo Lee $\cdot$ Soo-Teik Lee $・$ \\ Tae-Oh Kim • Yong-Woon Shin • Sang-Yong Seol
}

Published online: 21 August 2014

(C) The Pharmaceutical Society of Korea 2014

\section{Erratum to: Arch. Pharm. Res.}

DOI 10.1007/s12272-014-0408-3

Unfortunately, the authors have made mistakes in the original version of the article. The errors should be corrected as below:

The online version of the original article can be found under doi:10.1007/s12272-014-0408-3.

\section{O. Y. Lee}

Department of Internal Medicine, Hanyang University College of Medicine, Seoul, South Korea

\section{D.-H. Kang}

Department of Internal Medicine, Pusan National University

Yangsan Hospital, Busan, South Korea

D. H. Lee

Department of Internal Medicine, Seoul National University

Hospital of Bundang, Seongnam, South Korea

\section{I.-K. Chung}

Department of Internal Medicine, Soonchonhyang University Hospital Cheonan, Cheonan, South Korea

\section{J. Y. Jang}

Department of Internal Medicine, Kyung Hee University College of Medicine, Seoul, South Korea

\section{J.-I. Kim}

Department of Internal Medicine, The Catholic University of Korea Yeouido St.Mary's Hospital, Seoul, South Korea

\section{J.-W. Cho}

Department of Internal Medicine, Presbyterian Medical Center, Jeonju, South Korea

\section{In Title (Author)}

Line 2: Author 'Jae-Young Jang' should be corrected to 'Jae Young Jang.' The correct name of the author is shown in this erratum.

\section{In Abstract}

Lines 14-15: The sentence, 'A total of 236 patients received DA 9601 and 242 received misoprostol,' should be deleted.

In Keywords

Line 1: The word, 'Stilen ${ }^{\circledR}$, should be corrected to 'Stillen ${ }^{\circledR}$,'

\section{J.-S. Rew}

Department of Internal Medicine, Chonnam National University College of Medicine, Gwangju, South Korea

\section{K.-M. Lee}

Department of Internal Medicine, The Catholic University of Korea St.Vincent's Hospital, Suwon, South Korea

\section{K. O. Kim}

Department of Internal Medicine, Gacheon University Gil Medical Center, Incheon, South Korea

\section{M.-G. Choi}

Department of Internal Medicine, The Catholic University of Korea Seoul St.Mary's Hospital, Seoul, South Korea

\section{S.-W. Lee}

Department of Internal Medicine, Korea University Ansan Hospital, Ansan, South Korea

\section{S.-T. Lee}

Department of Internal Medicine, Chonbuk National University Hospital, Jeonju, South Korea

\section{T.-O. Kim}

Department of Internal Medicine, Inje University Haeundae Paik Hospital, Busan, South Korea 
Table 6 Difference of mean total scores for GI symptoms at week 0 and week 4

\begin{tabular}{|c|c|c|c|c|c|}
\hline \multirow[b]{3}{*}{ Week 0} & \multicolumn{2}{|c|}{ DA-9601 } & \multicolumn{2}{|c|}{ Misoprostol } & \multirow[t]{2}{*}{$P$ value } \\
\hline & \multicolumn{4}{|c|}{$\begin{array}{l}\mathrm{n}, \text { mean } \pm \text { S.D., } \\
\text { median, min, } \max \end{array}$} & \\
\hline & 236 & $\begin{array}{l}1.4 \pm 2.5 \\
0.0,0.0 \\
19.0\end{array}$ & 242 & $\begin{array}{l}1.1 \pm 2.0 \\
0.0,0.0 \\
\quad 9.0\end{array}$ & $0.1126^{\mathrm{a}}$ \\
\hline Week 4 & 232 & $\begin{array}{l}1.2 \pm 2.2 \\
0.0,0.0 \\
14.0\end{array}$ & 240 & $\begin{array}{l}2.3 \pm 3.3 \\
1.0,0.0 \\
22.0\end{array}$ & \\
\hline $\begin{array}{l}\text { Difference } \\
\text { between } \\
\text { week } 0 \text { and } \\
\text { week } 4\end{array}$ & 232 & $\begin{array}{l}-0.2 \pm 2.8 \\
0.0,-15.0 \\
14.0\end{array}$ & 240 & $\begin{array}{l}1.2 \pm 3.2 \\
0.0,-6.0 \\
22.0\end{array}$ & $<0.0001^{\mathrm{a}^{\dagger}}$ \\
\hline$P$ value & & $0.1355^{\mathrm{b}}$ & & $<0.0001^{\mathrm{b} \dagger}$ & \\
\hline
\end{tabular}

\section{In Table 1}

The heading (score) and the contents of score such as 0,1 , 2 etc. in Table 1 should be center-aligned.

\section{In Materials and methods section}

Study design-Line 12: The number '100' should be corrected to '200.'

Ethics statement-Line 24: The number ' 15 ' should be corrected to '3-2012-0098.'

\section{In Table 6}

In the table, the contents of Misoprostol should be aligned with its heading. In the original version of the article, the heading of Misoprostol leans far to the left. Also, the 3rd line of the table should be all connected. ' $n$, mean \pm S.D., median, min, max,' 'DA-9601' and 'Misoprostol' should be center-aligned. The correct version of Table 6 is shown below:

Y.-W. Shin

Department of Internal Medicine, Inha University Hospital, Incheon, South Korea

\section{S.-Y. Seol (ه)}

Department of Internal Medicine, Inje University Busan Paik Hospital, 75 Bokji-ro, Busanjin-gu, Busan 614-735, Korea e-mail: seolsymd@hanmail.net 